\title{
Genotype association of IP6K3 gene with Hashimoto's thyroiditis in Algerian population (Aures region)
}

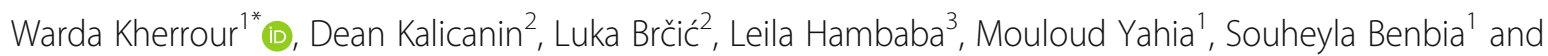
Vesna Boraska Perica²

\begin{abstract}
Background: Hashimoto's thyroiditis (HT) is a chronic autoimmune disease of the thyroid gland and is also the main cause of hypothyroidism. A recent genome-wide association study (GWAS) suggested an association of three novel genetic variants with HT in a population of Caucasian origin (Croatian). A case-control study was performed to investigate the association of these three newly suggested genetic variants with $\mathrm{HT}$ in a non-Caucasian ethnic group, an Arab-Berber from Algeria.

Three variants (rs12944194 located 206 kb from SDK2, rs791903 inside IP6K3, and rs75201096 inside GNA14) were genotyped using real-time PCR.

Results: There were no significant differences in allele frequencies of the three genetic variants between HT cases and controls. However, the present study showed nominal significance in the genotype distribution of rs791903 (IP6K3 gene) between HT patients and the control group $(P=0.024)$; we observed a decrease in the frequency of rs791903 recessive homozygotes $(C C)$ in $H T$ cases versus controls ( $O R=0.476, P=0.025)$.

Conclusion: This is the first study that showed the genotypic association of IP6K3 intronic variant with decreased risk for HT in non-Caucasian, Algerian, population, whereas we did not confirm the association of SDK2 and GNA14 genetic variants with HT. The IP6K3 gene (inositol hexaphosphate kinase 3), located near major histocompatibility complex (MHC), has previously been associated with other common autoimmune diseases beside HT, such as Graves's disease and rheumatoid arthritis, which is providing more evidence of a good candidacy for the genetic contribution to the development of HT and autoimmunity.
\end{abstract}

Keywords: Hashimoto's thyroiditis, IP6K3 gene, rs791903 variant, Real-time PCR, Genetic association study, Algerian population

\section{Background}

Hashimoto's thyroiditis (HT), also known as chronic lymphocytic thyroiditis, is the most common form of autoimmune thyroid disease. HT is characterized by chronic inflammation of the thyroid gland and synthesis

\footnotetext{
* Correspondence: w.kherrour@univ-batna2.dz

'Biotechnology's Laboratory of the Bioactive Molecules and the Cellular Physiopathology, Department of Biology of Organisms, Faculty of Natural and Life Sciences, University of Batna 2, 53, Route of Constantine. Fesdis, 05078 Batna, Algeria

Full list of author information is available at the end of the article
}

of thyroid peroxidase antibodies (TPO Ab) and/or thyroglobulin antibodies (TG Ab) [1]. The pathogenesis of this autoimmune disease is complex, and it is generally accepted that the infiltration of $\mathrm{T}$ lymphocytes and plasma cells leads to the destruction of thyroid tissue $[2,3]$.

HT is the most common cause of hypothyroidism in areas with excess iodine intake $[4,5]$. On the worldwide scale, it is reported that the incidence of HT is higher in women than men $(0.28$ per 1000 population/year for women and 0.03 per 1000 population/year for men) [6]. 
In addition, according to Chabchoub et al. [7], the prevalence of HT is estimated to be $22.8 \%$ in Africa.

HT is multifactorial autoimmune diseases where interaction between genetic and environmental factors plays an important role [8-10]. Many recent studies also pointed the role of epigenetic modifications in HT pathogenesis [11]. However, family and twin studies suggested that genetic factors are the main drivers of HT. It is estimated that genetic predisposition contributes to about $80 \%$ to HT development $[7,12]$.

Several genetic studies suggested the contribution of two types of genes to HT susceptibility: immune regulatory genes (HLA-DR, CTLA-4, PTPN22) [13] and thyroid-specific ones (TG and TPO) [14]. Recently, several other genes (IL15, IL27, FOXP3, and SEPS1) have also been suggested to be associated with HT [15-18].

A first genome-wide association analysis (GWAS) on patients with autoimmune thyroid disease (AITD) used ImmunoChip and identified the association of four loci with HT: 2p25.1, 3q27.3/3q28, 6q15, and 11q21 [19]. Additionally, another GWAS by Inoue et al. [20] reported the association of ZFAT gene with HT severity but not with its development. Another GWAS by Oryoji et al. [21] directly compared HT and GD cases and indicated the association of rs7537605 in the VAV3 locus with HT. Finally, a GWAS by Eriksson et al. [22] has shown the association of rs6679677 near PTPN22, rs3184504 in $S H 2 B 3$, and rs2517532 in the HLA class I region with a large spectrum of autoimmune diseases.

Importantly, there was only one GWAS that focused exclusively on HT to date. That study was performed in the Croatian population and included 405 cases and 433 controls, followed up by replication in 303 cases and 302 controls from two replication cohorts [23]. That study suggested an association of three novel HT variants: rs12944194 located $206 \mathrm{~kb}$ from SDK2, rs791903 inside IP6K3, and rs75201096 inside GNA14 [23]. These three genetic variants are located in genomic regions with good biological candidacy to HT/autoimmunity and with the regulation of thyroid function.

The main aim of our study was to analyze the association of these three newly suggested genetic variants with HT in a different ethnic group than originally reported, the non-Caucasian, Arab-Berber population from Algeria.

\section{Methods}

\section{Subjects}

We performed a case-control study that included one hundred patients with HT and one hundred and twentysix healthy subjects from the Aures region of Algeria that belong to an Arab-Berber ethnic group. Cases and controls were recruited in the period of 2 years (from January 2016 to February 2018).
HT patients (96\% of women), with a median age of 39.5 years and median body mass index (BMI) of $27.26 \mathrm{~kg} / \mathrm{m}^{2}$, were recruited from three clinics: El Balsem el Chafy (Khenchela), Endocrinology \& Metabolism Clinics of Dr. Mallem and Endocrinology \& Metabolism Clinics of Dr. Heddar (Batna). HT was diagnosed by specialists in nuclear medicine based on several criteria that included clinical symptoms, ultrasound findings, biochemical measurements of thyroid-stimulating hormone (TSH), and thyroid antibody (TPO Ab), according to European Thyroid Association (ETA) guidelines (Management of Subclinical Hypothyroidism) [24]. All HT patients had high levels of $\mathrm{TSH}$ and TPO-Ab and were treated with levothyroxine sodium (Merck KGaA, Frankfurter Str. 250, Darmstadt, Germany). We excluded patients with a personal history of any other autoimmune disease.

A control group (64.3\% of women), with a median age of 33 years and a median BMI of $24.73 \mathrm{~kg} / \mathrm{m}^{2}$, were recruited from the University Hospital of Batna. All control participants were selected according to the following criteria: TPO Ab negative (5-34 UI/mL), TSH levels between 0.27 and $4.7 \mu \mathrm{IU} / \mathrm{mL}$, and FT4 levels between 12 and $22 \mathrm{pmol} / \mathrm{L}$. None of the control subjects had a personal history of HT or any other autoimmune disease.

Clinical and demographic characteristics of HT patients and the control group are presented in Table 1.

The study was approved by the scientific-ethical committee of the University Hospital of Batna, under the number 524. Informed consent was obtained from all participants and the study was conducted according to the Declaration of Helsinki.

\section{Blood samples and DNA extraction}

Venous blood was collected in EDTA tubes $(4 \mathrm{~mL})$ from all study participants and stored at $-80^{\circ}$ until extraction. Genomic DNA was extracted by the QIAamp DNA Blood Mini Kit (Qiagen, Hilden, Germany) according to the manufacturer's instructions. DNA concentration was measured using Nanodrop ND-1000 Spectrophotometer (ND-1000, Thermo Fisher Scientific, Waltham, MA, USA).

\section{Genotyping}

We selected single nucleotide polymorphisms (SNPs) (rs12944194, rs791903, and rs75201096) from the recently published GWAS of HT in Caucasian population [23]. SNP genotyping was performed by real-time PCR using ABI PRISM 7500 Sequence Detection System (Applied Biosystems, Foster City, USA) and predeveloped TaqMan SNP genotyping assays.

\section{Association analysis}

All statistical tests were performed by Plink software version 1.07 [25]. Prior association analysis, we checked if genotypes of the three investigated SNPs were 
Table 1 Clinical and demographic characteristics of HT patients and control group

\begin{tabular}{lll}
\hline Characteristics & HT $(N=100)$ & Control $(N=126)$ \\
\hline Gender, $n(\%)$ & & \\
$\quad$ Men & $4(4 \%)$ & $45(35.7 \%)$ \\
$\quad$ Women & $96(96 \%)$ & $81(64.3 \%)$ \\
Age (years) & $39.5(32.5-47.75)$ & $33(28-40)$ \\
BMI (kg/m $\left.{ }^{2}\right)$ & $27.26(24-30.19)$ & $24.73(23.04-26.68)$ \\
TPO Ab level (UI/mL) & $411.5(245.60-600)$ & $11.1(7.87-15.00)^{\mathrm{a}}$ \\
Log 10 of TPO Ab level & $2.57 \pm 0.26^{\mathrm{b}}$ & - \\
(mean \pm SD) & & \\
\hline
\end{tabular}

Data are presented by percentages for qualitative data and by a median with interquartile range (25-75th percentile) for quantitative data

${ }^{a}$ Reference values for TPO Ab levels: $5-34 \mathrm{UI} / \mathrm{mL}$

${ }^{\mathrm{b}} \mathrm{TPO}$ Ab level of HT patients is presented by mean \pm SD after a

logarithmic transformation

according to Hardy-Weinberg equilibrium (HWE) using an exact test [26]. Association of the three SNPs with HT was tested using a logistic regression model adjusted for age and BMI. Differences in the distribution of genotype frequencies of three SNPs were tested by Fisher's exact test. In addition, we checked the association of these three SNPs with TPO Ab levels in the group of HT cases only, using a linear regression model adjusted for age and BMI. A logarithmic transformation of TPO $\mathrm{Ab}$ levels in HT cases was performed prior analysis to ensure normal distribution.

Odds ratio (OR) and confidence intervals (95\% CI) were calculated using IBM SPSS Statistics for Windows, Version 20.0. (Armonk, NY: IBM Corp). We used Bonferroni corrected $P$ value of 0.017 (0.05 corrected for 3 SNPs) for declaring significant associations.

\section{Results}

Genotype distribution of all SNPs in HT patients and the control group was according to HWE (Table 2).

We did not detect significant allelic association of the three investigated SNPs with HT at the Bonferronicorrected significance threshold (Table 3). However, we observed nominal significance in the distribution of rs791903 genotype $(P=0.024)$ between HT and the control group. Recessive homozygotes $(\mathrm{CC})$ were less frequent in HT cases than in controls $(P=0.025)$ (Table 4 ).
No associations were detected with TPO Ab levels in the group of HT patients (Table 5).

\section{Discussion}

The goal of our study was to explore the association of three newly suggested HT-associated genetic variants with the risk of developing HT in 100 HT patients and 126 controls of Arab-Berber ethnicity. To our knowledge, this is the first genetic study that focused on the evaluation of the association of these genetic variants (rs12944194, rs791903, and rs75201096) with susceptibility to HT in non-Caucasian population from Algeria. Our main result is the observation of a nominally significant decrease in the frequency of rs791903 recessive genotype in HT cases versus controls.

The original GWAS study, performed by Brčić et al. [23], showed an association of rs12944194, rs791903, and rs75201096 genetic variants with HT in Croatian population. The present study did not confirm the allelic association of these three SNPs and HT in our population. However, we observed that the rs791903 recessive homozygotes $(\mathrm{CC})$ were significantly less frequent in HT patients than in controls $(P=0.025, \mathrm{OR}=0.476)$ (Table 4$)$.

Genetic variant rs791903 is located in the intronic region of inositol hexaphosphate kinase 3 (IP6K3) gene on chromosome 6 (6p21). This locus has already been strongly associated with several inflammatory and autoimmune diseases [27-29].

A recent study observed association of rs791903 with rheumatoid arthritis (RA) [30], which is an autoimmune diseases that is also present in $4.25 \%$ of patients with HT [31]. It is suggested that HT and RA share genetic background and our study adds more evidence to genetic contribution of rs791903 in, both, RA and HT. Furthermore, it has been reported that IP6K3 gene is expressed in the thyroid tissue [32], but until now, its exact role remains unclear.

Several HT-related autoimmune diseases, such as systemic lupus erythematosus (SLE), GD, and RA, were already associated with genetic variants in ITPR3 gene that belongs to thyroid hormone synthesis pathway [33]. ITPR3 gene is located very near to our SNP rs791903 (38 kb away). According to Oishi et al. [33], the rs3748079, located in the promoter region of ITPR3 gene

Table 2 SNP characteristics in HT patients and control group

\begin{tabular}{|c|c|c|c|c|c|c|}
\hline SNP & Chr & Position & MAF HT patients ${ }^{a}$ & MAF control group ${ }^{\mathrm{b}}$ & $P$ (HWE) HT patients ${ }^{c}$ & $P$ (HWE) control group ${ }^{d}$ \\
\hline rs12944194 & 17 & 71846563 & 0.365 & 0.361 & 0.280 & 0.564 \\
\hline rs791903 & 6 & 33702645 & 0.455 & 0.496 & 0.072 & 0.076 \\
\hline rs75201096 & 9 & 80098900 & 0.025 & 0.0119 & 1.0 & 1.0 \\
\hline
\end{tabular}

Chr chromosome

${ }^{a}$ MAF minor allele frequency of HT patients

${ }^{\mathrm{b}} \mathrm{MAF}$ minor allele frequency of control group

${ }^{c} P$ value for Hardy-Weinberg equilibrium test in HT patients

${ }^{d} P$ value for Hardy-Weinberg equilibrium test in the control group 
Table 3 Results of Association analysis for rs12944194, rs791903, and rs75201096 in HT case-control analysis

\begin{tabular}{llllll}
\hline SNP & Gene/nearest gene & MA & OA & OR $(95 \%$ Cl $)$ & $P$ value \\
\hline rs12944194 & SDK2 (206 kb away) & T & C & $1.016(0.623-1.654)$ & 0.934 \\
rs791903 & IP6K3 & C & G & $0.849(0.520-1.384)$ & 0.387 \\
rs75201096 & GNA14 & C & T & $2.158(0.318-14.63)$ & 0.300 \\
\hline
\end{tabular}

$M A$ minor allele, $O A$ other allele, $O R$ odds ratio, $C l$ confidence interval

and $114 \mathrm{~kb}$ from rs791903 $\left(D^{\prime}=0.671, r^{2}=0.1557\right)$, was strongly associated with SLE in Japanese population. Also, two other markers of the same gene, rs9394159 and rs4713693, were associated with GD [34]. Genetic studies of AITD showed the existence of a common genetic background between HT and GD [35-37]. Almost $74 \%$ of SNPs related to GD have the same effect on HT [23]; therefore, the genetic overlap between HT and GD, as supported by our study, gives additional evidence of the role of this SNP in AITD.

The most important limitation of our study is the sample size. Future studies of the genetic background of HT in our ethnic group should include larger sample sizes to confirm the results from this study. It is important to note that there is a difference in gender distribution between our case and control group: our case group consists of $96 \%$ women (as is expected for this female prevalent disease) $[38,39]$ whereas the control group consists of $64.3 \%$ of women. The difference in the gender distribution between cases and controls should not affect our results as the latest scientific reports encourage using mixed-sex controls (those consisted of both males and females) in studies of sex-specific traits (such as HT, which is predominantly affecting women). This largest genetic study including 61,094 women and 53, 769 men showed that there are no allele frequency
Table 5 Results of association analysis of three SNPs with TPOAb levels

\begin{tabular}{llll}
\hline SNP & $\begin{array}{l}\text { Minor } \\
\text { allele }\end{array}$ & TPO Ab & \\
\cline { 3 - 4 } & & $\beta(S E)$ & $P$ value \\
\hline rs12944194 & $T$ & $-0.0159(0.0337)$ & 0.6365 \\
rs791903 & $C$ & $-0.0276(0.0383)$ & 0.4724 \\
rs75201096 & $C$ & $-0.0173(0.1113)$ & 0.8763 \\
\hline
\end{tabular}

$\beta$ linear regression slope coefficient, SE standard error

differences at common SNPs between men and women [40]. The advantages of our study include the stringent selection of HT patients, which are characterized by the presence of significantly higher levels of TPO Ab than controls $(<0.001)$. Our patients also had a higher BMI than controls, which is in line with the observations from most studies [41]. Another advantage is the careful selection of controls in clinical settings. We excluded individuals with any type of thyroid or any other autoimmune disorder from controls. Controls had TPO Ab levels in the reference ranges, thus minimizing potential bias (Table 1).

Finally, it is now a common practice to analyze genetic variants in different ethnic groups than originally reported, as we now know that differences in the strength and even the direction of genetic signals across different populations exist. We believe that results of our study add to the current scientific knowledge on genetic susceptibility to HT. However, in the present time, when genetic influence on HT is just starting to be deciphered, there is no translational benefit for study subjects. Therefore, it is important to continue these efforts and perform replication studies and additional functional studies using other high-throughput analytic methods, to understand the mechanisms by which IP6K3 gene

Table 4 Genotype association of rs12944194, rs791903, and rs75201096 with HT

\begin{tabular}{|c|c|c|c|c|c|c|c|c|}
\hline \multirow{2}{*}{$\frac{\text { SNPS }}{\text { rs12944194 }}$} & \multicolumn{3}{|l|}{$\mathrm{HT}, n(\%)$} & \multicolumn{3}{|c|}{ Control group, $n(\%)$} & \multirow[t]{2}{*}{ OR $(95 \% \mathrm{Cl})$} & \multirow[t]{2}{*}{$P$ value } \\
\hline & $\pi$ & $\mathrm{TC}$ & CC & $\pi$ & $\mathrm{TC}$ & CC & & \\
\hline & $16(16 \%)$ & $41(41 \%)$ & $43(43 \%)$ & $18(14.2 \%)$ & $55(43.7 \%)$ & $53(42.1 \%)$ & - & 0.899 \\
\hline & \multicolumn{6}{|c|}{ TT + TC vs. CC (dominant model) } & $0.962(0.566-1.637)$ & 0.887 \\
\hline & \multicolumn{6}{|c|}{ TT vs. TC + CC (recessive model) } & $1.143(0.550-2.375)$ & 0.720 \\
\hline \multirow[t]{4}{*}{ rs791903 } & $\mathrm{CC}$ & CG & GG & $\mathrm{CC}$ & CG & GG & & \\
\hline & $16(16 \%)$ & $59(59 \%)$ & $25(25 \%)$ & $36(28.6 \%)$ & $53(42.1 \%)$ & $37(29.3 \%)$ & - & 0.024 \\
\hline & \multicolumn{6}{|c|}{ CC + CG vs. GG (dominant model) } & $1.247(0.689-2.257)$ & 0.465 \\
\hline & \multicolumn{6}{|c|}{ CC vs. CG + GG (recessive model) } & $0.476(0.246-0.921)$ & 0.025 \\
\hline \multirow[t]{4}{*}{ rs75201096 } & CC & $\mathrm{CT}$ & $\pi$ & $\mathrm{CC}$ & $\mathrm{CT}$ & $\pi$ & & \\
\hline & $0(00 \%)$ & $5(5 \%)$ & $95(95 \%)$ & $0(00 \%)$ & $3(2.4 \%)$ & $123(97.6 \%)$ & - & 0.471 \\
\hline & \multicolumn{6}{|c|}{$C C+C T$ vs. $T$ (dominant model) } & $2.158(0.503-9.256)$ & 0.471 \\
\hline & \multicolumn{6}{|c|}{ CC vs. $C T+\Pi T$ (recessive model) } & - & 1.0 \\
\hline
\end{tabular}


exerts its roles in HT. The final aim in the future is to benefit patients by translating new knowledge on genetic factors (thus biological mechanisms) into clinical practice.

\section{Conclusion}

In conclusion, this is the first genetic study that was focused on understanding the genetic basis of HT in Algerian population. Our results suggest the lack of allelic association of rs12944194, rs791903, and rs75201096 with HT. However, we found differences in the genotype distribution of rs791903 between HT and the control group, where recessive homozygotes $(\mathrm{CC})$ were significantly less frequent in HT patients.

Due to the increased prevalence of HT in the ArabBerber ethnical group from Algeria, future large-scale casecontrol studies are necessary for replication of our results.

\section{Abbreviations \\ HT: Hashimoto's thyroiditis; IP6K3 gene: Inositol hexaphosphate kinase 3 gene; MHC: Major histocompatibility complex; TPO Ab: Thyroid peroxidase antibody; TG Ab: Thyroglobulin antibody; GWAS: Genome-wide association studies; AITD: Autoimmune thyroid disease; GD: Graves' disease; \\ ETA: European Thyroid Association; BMI: Body mass index; SNP: Single nucleotide polymorphism; HWE: Hardy-Weinberg equilibrium; OR: Odds ratio; RA: Rheumatoid arthritis; SLE: Systemic lupus erythematosus}

\section{Acknowledgements}

The study was supported by International Center for Genetic Engineering and Biotechnology (ICGEB) Trieste, Italy; Department of Medical Biology, University of Split School of Medicine, Split, Croatia; and Laboratory of Biotechnology of Bioactive Molecules and Cell Pathophysiology, The Directorate General for Scientific Research and Technological Development (DG-RSDT), Algeria.

We are grateful for Dr. Rachid Lahmari, Dr. Adel Guellouh, and all doctors of El Balsem el Chafy clinics (Khenchela) and Dr. Noureddine Mallem and Dr. Noureddine Heddar from Endocrinology \& Metabolism Clinics (Batna) to accept us within their clinics and for their guidance.

We thank all healthy volunteers and patients who agreed to participate in our study. Big grateful is given to University Hospital of Batna, Saad Laoud, Ibn Sina, and Nezar laboratories, Batna, Algeria, for their help in sample collection.

\section{Authors' contributions}

MY, SB, LH, and VBP supervised and conceived study conception and design. WK participated in data collection and/or processing. WK, DK, VBP, and LB carried out the molecular genetic work, the statistical analysis, and interpretation. WK, VBP, and DK drafted the manuscript. All authors read and approved the final manuscript and accepted the publication.

\section{Funding}

None.

\section{Availability of data and materials}

The data used or analyzed during the study are available from the corresponding author.

\section{Ethics approval and consent to participate}

The study was approved by scientific committee of University Hospital of Batna, under the number 524. Informed written consent was obtained from all participants. Reference number: not applicable.

\section{Consent for publication}

Not applicable.

\section{Competing interests}

The authors declare that they have no competing interests

\begin{abstract}
Author details
'Biotechnology's Laboratory of the Bioactive Molecules and the Cellular Physiopathology, Department of Biology of Organisms, Faculty of Natural and Life Sciences, University of Batna 2, 53, Route of Constantine. Fesdis, 05078 Batna, Algeria. ${ }^{2}$ Department of Medical Biology, University of Split School of Medicine, Split, Croatia. 'Biotechnology's Laboratory of the Bioactive Molecules and the Cellular Physiopathology, Department of Microbiology and Biochemistry, Faculty of Natural and Life Sciences, University of Batna 2, Batna, Algeria.
\end{abstract}

Received: 10 February 2020 Accepted: 23 July 2020

Published online: 27 November 2020

\section{References}

1. Kotani T, Aratake Y, Hirai K, Fukazawa Y, Sato H, Ohtaki S (1995) Apoptosis in thyroid tissue from patients with Hashimoto's thyroiditis. Autoimmunity 20: 231-236 https://doi.org/10.3109/08916939508995700

2. Roitt IM, Doniach D, Campbell PN, Vaughan Hudson R. Auto-antibodies in Hashimoto's disease (lymphadenoid goitre). Lancet 1956;268:820-821. https://doi.org/10.1016/S0140-6736(56)92249-8.

3. Lin J-D (2001) The role of apoptosis in autoimmune thyroid disorders and thyroid cancer. BMJ 322:1525-1527 https://doi.org/10.1136/bmj.322.7301. 1525

4. Reinhardt W, Luster M, Rudorff K, Heckmann C, Petrasch S, Lederbogen S et al (1998) Effect of small doses of iodine on thyroid function in patients with Hashimoto's thyroiditis residing in an area of mild iodine deficiency. Eur J Endocrinol:23-28 https://doi.org/10.1530/eje.0.1390023

5. Zois C, Stavrou I, Kalogera C, Svarna E, Dimoliatis I, Seferiadis K et al (2003) High prevalence of autoimmune thyroiditis in schoolchildren after elimination of iodine deficiency in northwestern Greece. Thyroid 13:485-489 https://doi.org/10.1089/105072503322021151

6. Seo GH, Chung JH (2015) Incidence and prevalence of overt hypothyroidism and causative diseases in Korea as determined using claims data provided by the health insurance review and assessment service. Endocrinol Metab 30:288 https://doi.org/10.3803/EnM.2015.30.3.288

7. Chabchoub G, Mnif M, Maalej A, Charfi N, Ayadi H, Abid M. Étude épidémiologique des maladies autoimmunes thyroïdiennes dans le sud tunisien. Ann Endocrinol 2006;67:591-595. https://doi.org/10.1016/S00034266(06)73012-8.

8. Jacobson EM, Tomer Y (2007) The CD40, CTLA-4, thyroglobulin, TSH receptor, and PTPN22 gene quintet and its contribution to thyroid autoimmunity: Back to the future. J Autoimmun 28:85-98 https://doi.org/10. 1016/j.jaut.2007.02.006

9. Ajjan R, Weetman A (2015) The pathogenesis of Hashimoto's thyroiditis: further developments in our understanding. Horm Metab Res 47:702-710 https://doi.org/10.1055/s-0035-1548832

10. Wiersinga WM (2016) Clinical relevance of environmental factors in the pathogenesis of autoimmune thyroid disease. Endocrinol Metab 31:213 https://doi.org/10.3803/EnM.2016.31.2.213

11. Coppedè $F$ (2017) Epigenetics and autoimmune thyroid diseases. Front Endocrinol 8:149 https://doi.org/10.3389/fendo.2017.00149

12. Brix TH, Kyvik KO, Hegedüs L (2000) A Population-based study of chronic autoimmune hypothyroidism in Danish twins ${ }^{1}$. J Clin Endocrinol Metab 85: 536-539 https://doi.org/10.1210/jcem.85.2.6385

13. Ban $Y$, Tomer $Y$ (2003) The contribution of immune regulatory and thyroid specific genes to the etiology of Graves' and Hashimoto's diseases. Autoimmunity 36:367-379 https://doi.org/10.1080/08916930310001603037

14. Ramesh BG, Bhargav PR, Rajesh BG, Vimala Devi N, Vijayaraghavan R, Aparna VB (2015) Genomics and phenomics of Hashimoto's thyroiditis in children and adolescents: a prospective study from Southern India. Ann Transl Med 3 https://doi.org/10.3978/j.issn.2305-5839.2015.10.46

15. Arakawa Y, Watanabe M, Takemura K, Inoue N, Hidaka Y, Iwatani Y (2017) The IL15 +96522 A>T functional polymorphism is related to the differentiation of Th17 cells and the severity of Hashimoto's disease. Int J Immunogenet 44:41-50 https://doi.org/10.1111/iji.12305

16. He W, Wang B, Mu K, Zhang J, Yang Y, Yao W et al (2019) Association of single-nucleotide polymorphisms in the IL27 gene with autoimmune 
thyroid diseases. Endocr Connect 8:173-181 https://doi.org/10.1530/EC-180370

17. Fathima N, Narne P, Ishaq M (2019) Association and gene-gene interaction analyses for polymorphic variants in CTLA-4 and FOXP3 genes: role in susceptibility to autoimmune thyroid disease. Endocrine 64:591-604 https:// doi.org/10.1007/s12020-019-01859-3

18. Li M, Liu B, Li L, Zhang C, Zhou Q (2015) Association studies of SEPS1 gene polymorphisms with Hashimoto's thyroiditis in Han Chinese. J Hum Genet 60:427-433 https://doi.org/10.1038/jhg.2015.42

19. Cooper JD, Simmonds MJ, Walker NM, Burren O, Brand OJ, Guo H et al (2012) Seven newly identified loci for autoimmune thyroid disease. Hum Mol Genet 21:5202-5208 https://doi.org/10.1093/hmg/dds357

20. Inoue $\mathrm{N}$, Watanabe $\mathrm{M}$, Yamada $\mathrm{H}$, Takemura $\mathrm{K}$, Hayashi F, Yamakawa $\mathrm{N}$ et al (2012) Associations between autoimmune thyroid disease prognosis and functional polymorphisms of susceptibility genes, CTLA4, PTPN22, CD40, FCRL3, and ZFAT, previously revealed in genome-wide association studies. J Clin Immunol 32:1243-1252 https://doi.org/10.1007/s10875-012-9721-0

21. Oryoji D, Ueda S, Yamamoto K, Yoshimura Noh J, Okamura K, Noda M et al (2015) Identification of a Hashimoto thyroiditis susceptibility locus via a genome-wide comparison with Graves' disease. J Clin Endocrinol Metab 100:E319-E324 https://doi.org/10.1210/jc.2014-3431

22. Eriksson N, Tung JY, Kiefer AK, Hinds DA, Francke U, Mountain JL et al (2012) Novel associations for hypothyroidism include known autoimmune risk loci. PLoS One 7:e34442 https://doi.org/10.1371/journal.pone.0034442

23. Brčić L, Barić A, Gračan S, Brekalo M, Kaličanin D, Gunjača I et al (2019) Genome-wide association analysis suggests novel loci for Hashimoto's thyroiditis. J Endocrinol Investig 42:567-576 https://doi.org/10.1007/s40618018-0955-4

24. Pearce SHS, Brabant G, Duntas LH, Monzani F, Peeters RP, Razvi $S$ et al (2013) 2013 ETA guideline: management of subclinical hypothyroidism. Eur Thyroid J 2:215-228 https://doi.org/10.1159/000356507

25. Purcell $S$, Neale B, Todd-Brown K, Thomas L, Ferreira MAR, Bender D et al (2007) PLINK: a tool set for whole-genome association and populationbased linkage analyses. Am J Hum Genet 81:559-575 https://doi.org/10. 1086/519795

26. Wigginton JE, Cutler DJ, Abecasis GR (2005) A note on exact tests of HardyWeinberg equilibrium. Am J Hum Genet 76:887-893

27. Laddha NC, Dwivedi M, Begum R (2012) Increased tumor necrosis factor (TNF)- $a$ and its promoter polymorphisms correlate with disease progression and higher susceptibility towards vitiligo. PLoS One 7:e52298 https://doi. org/10.1371/journal.pone.0052298

28. Yang S-K, Hong M, Zhao W, Jung Y, Baek J, Tayebi N et al (2014) Genomewide association study of Crohn's disease in Koreans revealed three new susceptibility loci and common attributes of genetic susceptibility across ethnic populations. Gut 63:80-87 https://doi.org/10.1136/gutjnl-2013-305193

29. Lee YH, Bae S-C, Song GG (2015) Meta-analysis of associations between functional HLA-G polymorphisms and susceptibility to systemic lupus erythematosus and rheumatoid arthritis. Rheumatol Int 35:953-961 https:// doi.org/10.1007/s00296-014-3155-3

30. the RACl consortium, the GARNET consortium, Okada Y, Wu D, Trynka G, Raj T et al (2014) Genetics of rheumatoid arthritis contributes to biology and drug discovery. Nature 506:376-381 https://doi.org/10.1038/nature12873

31. Boelaert K, Newby PR, Simmonds MJ, Holder RL, Carr-Smith JD, Heward JM, et al. Prevalence and relative risk of other autoimmune diseases in subjects with autoimmune thyroid disease. Am J Med 2010;123:183.e1-183.e9. https://doi.org/10.1016/j.amjmed.2009.06.030.

32. Moritoh Y, Oka M, Yasuhara Y, Hozumi H, Iwachidow K, Fuse H et al (2016) Inositol hexakisphosphate kinase 3 regulates metabolism and lifespan in mice. Sci Rep 6:32072 https://doi.org/10.1038/srep32072

33. Oishi T, lida A, Otsubo S, Kamatani Y, Usami M, Takei T et al (2008) A functional SNP in the NKX2.5-binding site of ITPR3 promoter is associated with susceptibility to systemic lupus erythematosus in Japanese population. J Hum Genet 53:151-162 https://doi.org/10.1007/s10038-007-0233-3

34. Nakabayashi K, Tajima A, Yamamoto K, Takahashi A, Hata K, Takashima Y et al (2011) Identification of independent risk loci for Graves' disease within the MHC in the Japanese population. J Hum Genet 56:772-778 https://doi. org/10.1038/jhg.2011.99

35. Zeitlin AA, Heward JM, Newby PR, Carr-Smith JD, Franklyn JA, Gough SCL et al (2008) Analysis of HLA class II genes in Hashimoto's thyroiditis reveals differences compared to Graves' disease. Genes Immun 9:358-363 https:// doi.org/10.1038/gene.2008.26
36. Ban Y, Tozaki T, Taniyama M, Nakano Y, Ban Y, Ban Y et al (2010) Association of the protein tyrosine phosphatase nonreceptor 22 haplotypes with autoimmune thyroid disease in the Japanese population. Thyroid 20:893899 https://doi.org/10.1089/thy.2010.0104

37. Yang J, Qin Q, Yan N, Zhu Y, Li C, Yang X et al (2012) CD40 C/T-1 and CTLA4 A/G49 SNPs are associated with autoimmune thyroid diseases in the Chinese population. Endocrine 41:111-115 https://doi.org/10.1007/s12020011-9510-1

38. Chiovato L, Lapi P, Fiore E, Tonacchera M, Pinchera A (1993) Thyroid autoimmunity and female gender. J Endocrinol Investig 16:384-391 https:// doi.org/10.1007/BF03348863

39. McGrogan A, Seaman HE, Wright JW, de Vries CS (2008) The incidence of autoimmune thyroid disease: a systematic review of the literature. Clin Endocrinol 69:687-696 https://doi.org/10.1111/j.1365-2265.2008.03338.x

40. Boraska V, Jerončić A, Colonna V, Southam L, Nyholt DR, William Rayner N et al (2012) Genome-wide meta-analysis of common variant differences between men and women. Hum Mol Genet 21:4805-4815 https://doi.org/ 10.1093/hmg/dds304

41. Poplawska-Kita A, Siewko K, Telejko B, Kosciuszko-Zdrodowska M, Hryniewicka J, Szelachowska M et al (2014) Body mass analysis in patients with Hashimoto thyroiditis. Endocr Abstr https://doi.org/10.1530/endoabs. 35.P978

\section{Publisher's Note}

Springer Nature remains neutral with regard to jurisdictional claims in published maps and institutional affiliations.

\section{Submit your manuscript to a SpringerOpen ${ }^{\circ}$ journal and benefit from:}

- Convenient online submission

- Rigorous peer review

- Open access: articles freely available online

High visibility within the field

- Retaining the copyright to your article

Submit your next manuscript at $\boldsymbol{\nabla}$ springeropen.com 